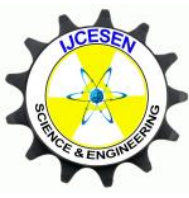

Copyright (C) IJCESEN
International Journal of Computational and

Experimental Science and $\boldsymbol{E N g i n e e r i n g}$

(IJCESEN)

Vol.5 -No.1 (2019) pp. 52-55

http://dergipark.gov.tr/ijcesen

Research Article

\title{
Experimental Comparison of Al5083 Alloy Subjected to Annealing and Equal-Channel Angular Pressing
}

\section{Mehmet ŞAHBAZ ${ }^{1,2 *}$,Hasan KAYA ${ }^{3}$, Aykut KENTLI' ${ }^{1}$, Mehmet UÇAR ${ }^{4}$, Serkan ÖĞÜT ${ }^{1}$, Kerim ÖZBEYAZ ${ }^{1}$}

\author{
${ }^{1}$ Marmara University, Faculty of Engineering, Mechanical Engineering Department, İstanbul-Turkey \\ ${ }^{2}$ Karamanoglu Mehmetbey University, Mechanical Engineering Department , 70100, Karaman, Turkey \\ ${ }^{3}$ Kocaeli University, Asım Kocabıyık Vocational School, Machine and Metal Technology Dep., Kocaeli-Turkey \\ ${ }^{4}$ Kocaeli University, Faculty of Technology, Department of Automotive Engineering, Kocaeli-Turkey
}

* Corresponding Author : mehmetsahbaz1@gmail.com ORCID: 0000-0001-6379-8345

\section{Article Info:}

DOI: $10.22399 /$ ijcesen. 394542

Received : 13 February 2018

Accepted : 04 March 2019

\section{$\underline{\text { Keywords }}$}

Al5083

ECAP

SPD

Microstructure

Hardness

\begin{abstract}
:
In this study, the hardness and electrical resistivity of Al5083 alloy were investigated after equal-channel angular pressing (ECAP) and annealing processes. The effects of the annealing and ECAP processes on the properties of the alloy were investigated, and the results of the processes were compared with each other. The major reason for the different results between the two processes was changes in the microstructure, which were observed by optical microscopy and scanning electron microscopy. The results showed that, ECAP decrease the grain size, in parallel with it increase the hardness and electrical resistivity of material.
\end{abstract}

\section{Introduction}

Equal-channel angular pressing (ECAP) is a wellknown severe plastic deformation (SPD) method. ECAP is indeed an extrusion method; however, to obtain ultrafine grains, it is carried out with the material at a temperature under its recrystallization temperature. The difference between ECAP and other plastic deformation methods is that it can be applied several times to the same material. In addition, traditional deformation methods decrease the toughness while increasing the hardness of a material. The material is thus made more brittle, which is undesirable in many applications. After the ECAP process, the geometrical shape or the crosssection of the material is unchanged; the workpiece can therefore be passed numerous times through the ECAP die, further reducing the grain size with each pass. This process increases the hardness and strength of the material according to the Hall-Petch relationship (Eq.1), without affecting the toughness. The Hall-Petch equation is given as $\sigma_{a}=\sigma_{0}+\frac{k}{\sqrt{d}}$

where $\sigma_{a}$ is the yield stress for a polycrystalline material, $\sigma_{0}$ is yield stress for a single crystal, $k$ is a constant, and $d$ is the grain size. ECAP is generally used for nonferrous alloys of aluminum, magnesium, and copper because of their excellent properties. ECAP-treated materials can be used in numerous application fields, including machine parts that require high toughness, aerospace devices that require lightweight materials and defense vehicles that require high strength [1-7]. In the present study, we investigate the hardness and electrical resistivity of A15083 alloy specimens subjected to ECAP and annealing processes [8-9].

\section{Materials and Methods}

In this study, AA5083 was selected for workpieces because of its high strength among non-heatable alloys. Impax Supreme (1.2738) steel was used to 
produce the hexa-die, whereas 1.2344 steel was used for the pins (or top die). The pressing process was carried out using a 120-ton-capacity hydraulic press, and a high-temperature industrial furnace was used for the annealing and heating processes. The workpiece was produced from extruded bulk material as a cylinder with a diameter of $20 \mathrm{~mm}$ and a length of $55 \mathrm{~mm}$. The traditional ECAP process was selected as the processing method; the applied steps are described in section 2.1.

\subsection{Experimental Setup}

Firstly, the workpieces were homogenized at $520^{\circ} \mathrm{C}$ for $2 \mathrm{~h}$ and then cooled to room temperature by natural convection. Secondly, the specimen and die were heated to $350^{\circ} \mathrm{C}$ for pressing. After the specimen was lubricated with $\mathrm{MoS}_{2}$, it was pressed using a hydraulic press along the channel of the hexa-die. The channel angle and corner angle of the hexa-die were $90^{\circ}$ and $0^{\circ}$, respectively. The pressing speed was constant at $1 \mathrm{~mm} / \mathrm{s}$ in these experiments. During the pressing operation, the workpiece was positioned in the top channel of the die and pressed with the top die, as shown in Figure 1. The channel used for pressing was left open, whereas the other channels were closed with pins. The sample flowed through the open channel under the applied hydraulic force. In Figure 2a, half of the hexa-die is shown along with the workpiece and pins after the pressing operation. Figure $2 \mathrm{~b}$ shows the pressed sample after ejection from the die.

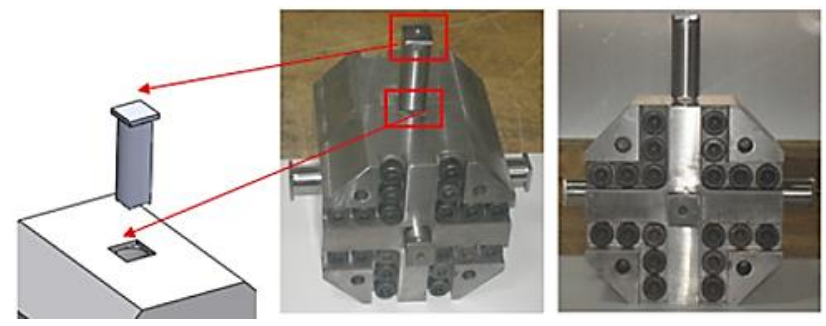

Figure 1. A schematic and pictures of the hexa-die with pins [4]

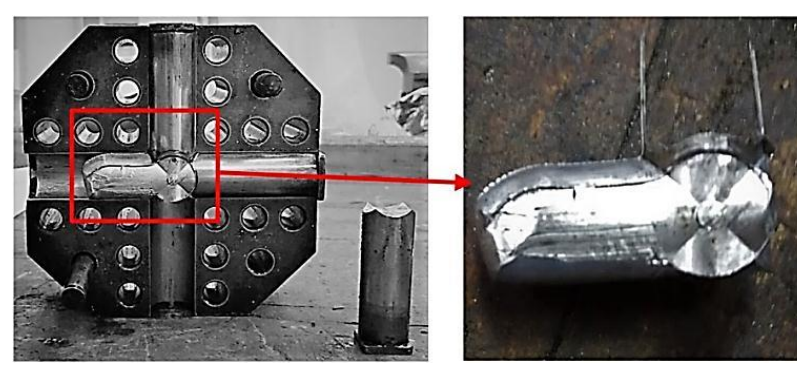

Figure 2. The pressed sample a) in the hexa-die and b) after ejection from the die

\subsection{Tests and Analyses}

After the ECAP process, three samples were prepared for tests and comparisons of each process. The first sample was in the as-received state (prehardened), the second sample was annealed, and the third sample was that obtained after the ECAP process. The samples were prepared for metallographic examination using optical microscopy $(\mathrm{OM})$ and scanning electron microscopy (SEM) to measure their grain sizes. For these observations, the samples were molded with Bakelite and then finely ground, polished, and etched. OM and SEM observations in conjunction with energy-dispersive X-ray spectroscopy (EDS) measurements were then performed. The electrical resistivity and hardness of the samples were subsequently measured.

\section{Results and Discussion}

This part of the paper includes the result and discussion of the all applied test on three state of AA5083 before and after ECAP operation. The tests can be ordered as OM and SEM imaging, EDS analysis, electrical resistivity and hardness tests.

\subsection{Optical Microscopy}

OM was used to assess whether the surface of each sample was suitable for SEM analysis. For this aim specimens were prepared with sandpapers and diamond cloths, then etched with Keller's reagent. Figure 3 shows, from left to right, OM images of the as-received, annealed, and ECAP-treated samples with $100 \mu \mathrm{m}$ scales. These images reveal that, compared with the as-received sample, the annealed sample exhibits reduced porosity and the ECAPtreated sample exhibits a smaller average grain size.

\subsection{SEM and EDS Analyses}

SEM was used to observe and measure the fine grain sizes of the samples for comparison. The same precipitations were observed at the grain boundaries of all of the samples; these precipitations resist dislocation propagation and increase the strength in the ECAP-treated sample, whereas they increase the electrical conductivity of the annealed sample. Below figure presents, SEM image of the ECAPtreated samples. After that, EDS spectrum of the AA5083 alloy and its corresponding chemical composition are shown in Figure 4. 


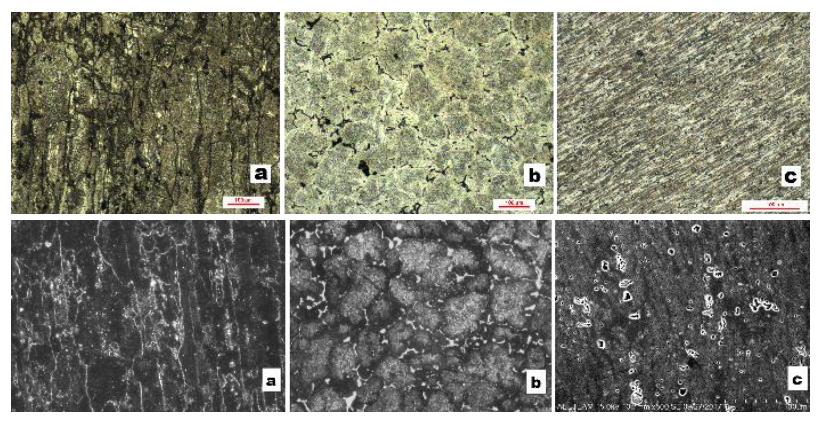

Figure 3. OM and SEM micrographs of the a) asreceived, b) annealed, c) ECAP-treated samples

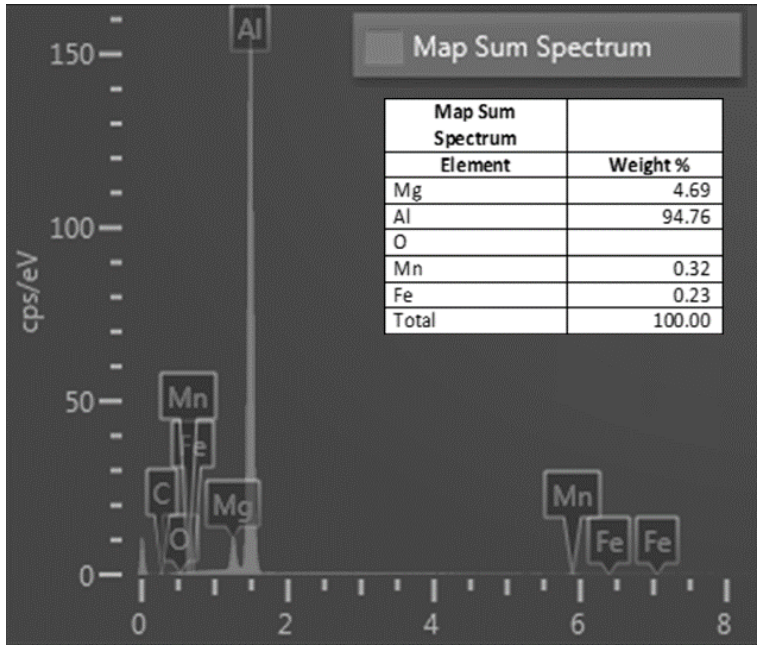

Figure 4. EDS spectrum and the corresponding chemical composition of the AA5083 alloy

\subsection{Electrical Resistivity}

Electrical resistivity tests were performed on the surfaces of the three workpieces using a four-point probe device. During the tests, a constant current was supplied to the sample via the two outside probes and the voltage was measured by the two inner probes. At the end of the tests, the measured voltages for all of the samples differed from the electrical resistivity calculated using the main equation. The electrical resistivity of the as-received AA5083 was $5.9 \times 10^{-6} \Omega . \mathrm{cm}$; the samples subjected to the annealing and ECAP processes exhibited minimal lower and higher electrical resistivity values, respectively. It showed that, grain size change with SPD has negligible effect on the electrical resistivity of AA5083 material [10].

\subsection{Hardness Test}

The Vickers method was used for the hardness tests; the test parameters included an applied load of 1000 $\mathrm{g}$ and a dwell time of $9 \mathrm{~s}$. The annealing process decreased the hardness, whereas the ECAP process increased it, as expected (Table 1).
Table 1. Vickers hardness of samples

\begin{tabular}{|l|c|}
\hline Sample & $\begin{array}{c}\text { Vickers } \\
\text { Hardness }\end{array}$ \\
\hline As-received & 91.6 \\
\hline Annealed & 80.3 \\
\hline ECAP-treated & 121.1 \\
\hline
\end{tabular}

The annealing process increased the grain size of the material and eliminated some inner stresses; thus, the hardness of the material decreased. By contrast, the ECAP process substantially decreased the grain size of the material, resulting in an increase in hardness.

\section{Conclusion}

Al5083 alloy was investigated, and the workpieces in the annealed, ECAP-treated, and as-received (unprocessed) states were subjected to hardness tests and electrical resistivity tests. OM, SEM, and EDS analyses were carried out to characterize the change of the grain size of the material. The obtained results are summarized as follows:

- Hardness increased as a result of the ECAP process, whereas it decreased as a result of the annealing process.

- Electrical resistivity (at the least) increased as a result of the annealing process, whereas it decreased as a result of the ECAP process.

- OM and SEM images showed that the average grain size decreased as a result of the ECAP process, whereas it increased as a result of the annealing process and some precipitations formed at the grain boundaries.

- EDS analyses showed that the chemical composition was nearly same after each treatment.

\section{Acknowledgment}

This work was supported by the Marmara University Scientific Research Project within project number FENC-DRP-120417-0183. Paper presented as abstract at " $4^{\text {rd }}$ International Conference on Computational and Experimental Science and Engineering (ICCESEN2017)”

\section{References}

[1] Valiev, R. Z., Islamgaliev, R. K., Alexandrov, I. V. "Bulk nanostructured materials from severe plastic deformation". Progress in Materials Science, 45(2), pp. 103-189. 2000. DOI:10.1016/S00796425(99)00007-9

[2] Valiev, R. Z., Langdon, T. G. "Principles of equalchannel angular pressing as a processing tool for grain 
refinement". Progress in Materials Science, 51(7), pp. 881-981, 2006. DOI: 10.1016/j.pmatsci.2006.02.003

[3] Kaya, H., Uçar, M. "The effects of mechanical properties on fatigue behavior of ecap' ed aa7075". High temperature materials and processes, 35(3), pp. 225-234, 2016. DOI: 10.1515/htmp-2014-0193

[4] Kaya, H., Uçar, M., Cengiz, A., Samur, R., Özyürek, D., Çalişkan, A. "Novel molding technique for ECAP process and effects on hardness of AA7075". Mechanika, 20 (1), pp. 5-10, 2014. DOI: 10.5755/j01.mech.20.1.4207

[5] Need, R.F., Alexander, D.J., Field, R.D., Livescu, V., Papin, P., Swenson, C.A., Mutnick, D.B. "The effects of equal channel angular extrusion on the mechanical and electrical properties of alumina dispersionstrengthened copper alloys". Materials Science and Engineering A, 565, pp. 450-458, 2013. DOI: $10.1016 /$ j.msea.2012.12.007.

[6] Singh, D., Jayaganthan, R., Nageswara Rao, P., Kumar, A. \& Venketeswarlu, D. 'Effect of initial grain size on microstructure and mechanical behavior of cryorolled AA 5083', Materials Today: Proceedings, 4 (8), pp. 7609-17, 2017. DOI: 10.1016/j.matpr.2017.07.094

[7] Esgin, U., Özyürek, D., KAYA, H. "Investigation of wear behavior of precipitation-strengthened nickelcopper based K-500 alloy produced by powder metallurgy". Acta Physica Polonica A, 129, pp. 544547, 2016. DOI: 10.12693/APhysPolA.129.544

[8] Chen, Y. J., Chai, Y. C., Roven, H. J., Gireesh, S. S., Yu, Y. D., \& Hjelen, J. "Microstructure and mechanical properties of $\mathrm{Al}-\mathrm{xMg}$ alloys processed by room temperature ECAP”. Materials Science and Engineering: A, 545, pp. 139-147, 2012. DOI: 10.1016/j.msea.2012.03.012

[9] Fakhar, N., Fereshteh-Saniee, F., \& Mahmudi, R. "High strain-rate superplasticity of fine- and ultrafinegrained AA5083 aluminum alloy at intermediate temperatures". Materials \& Design, 85, 342-348, 2015.DOI: 10.1016/j.matdes.2015.06.158

[10] Lipińska M, Bazarnik P, Lewandowska M. "The influence of severe plastic deformation processes on electrical conductivity of commercially pure aluminium and 5483 aluminium alloy". Archives of Civil and Mechanical Engineering, 16 (4), pp. 71723. 2016 DOI: /10.1016/j.acme.2016.04.013 